\title{
NO SABER Y NO RECONOCER: DOS METÁFORAS PARA PENSAR LA CRISIS DESDE LA RESURRECCIÓN DE JESÚS
}

\author{
NOT KNOWING AND NOT RECOGNIZING: TWO METAPHORS TO \\ THINK ABOUT THE CRISIS SINCE THE RESURRECTION OF JESUS
}

\author{
Juan Pablo Espinosa Arce ${ }^{1}$ \\ Pontificia Universidad Católica de Chile \\ ORCID: 0000-0002-2474-9185
}

Recibido: 20.04.2021

Aceptado: 20.05.2021

https://doi.org/10.21703/2735-6345.2021.22.02.001

\section{Resumen}

El presente artículo busca ofrecer una lectura espiritual a la crisis a partir de los conceptos de imaginario y metáfora. En la bibliografía se indica que dichas categorías favorecen una desmesura interpretativa de las imágenes tradicionales, poéticas, filosóficas, teológicas y bíblicas. Por medio de ellas se inaugura una nueva forma de interpretación de la realidad. A partir de ello, y de un modo más específico, se buscará pensar cómo la Resurrección de Jesús expresada en dos metáforas, "no saber" y no "reconocer", nos permite repensar y dar un nuevo significado a la crisis sanitaria, eclesial y sociopolítica actual.

Palabras clave. Imaginarios, gestos, metáforas, Resurrección de Jesús.

\begin{abstract}
This article seeks to offer a spiritual reading of the crisis based on the concepts of imaginary and metaphor. The bibliography indicates that these categories favor an excess of interpretation of traditional, poetic, philosophical, theological and biblical images. Through them a new form of interpretation of reality is inaugurated. Based on this, and in a more specific way, we will try to think about how the Resurrection of Jesus expressed in two metaphors, "not to know" and "not to recognized", allows us to rethink and give a new meaning to the current health, ecclesial and socio-political crisis.
\end{abstract}

Keywords. Imaginaries, gestures, metaphors, Resurrection of Jesus.

${ }^{1}$ Es Licenciado en Educación y Profesor de Religión y Filosofía por la Universidad Católica del Maule. Magíster en Teología Fundamental por la Pontificia Universidad Católica de Chile. Actualmente es académico Instructor Adjunto en la Facultad de Teología de la Pontificia Universidad Católica de Chile, académico de la Universidad Alberto Hurtado, Profesor del Seminario Metodista de Santiago de Chile y estudiante de doctorado en Teología en la Facultad de Teología de la Pontificia Universidad Católica de Chile. Correo electrónico: jpespinosa@uc.cl 


\section{1.- Presentación}

Si leemos con detención los relatos de la resurrección de Jesús presente en los Evangelios, podremos encontrar un elemento que transversalmente se repite en ellos, a saber, la incapacidad de los discípulos de reconocer al resucitado. Dos metáforas de la crisis de reconocimiento serán las que buscamos pensar en esta propuesta: el "no reconocer" en Emaús y el "no saber" de Magdalena y los discípulos pescando; ambos en el Evangelio de San Juan.

A nuestro entender, estas dos metáforas son parte de lo que, para efectos de este artículo, denominaré un imaginario de la crisis. Por este concepto busco entender la ausencia de referencias o puntos de anclaje y de crisis de subjetividades al interior de la comunidad cristiana las cuales, en cierta medida, pueden extrapolarse a la comunidad social y cultural actual, sobre todo a nuestra vivencia en medio de la pandemia.

La antropología del imaginario de la crisis es el elemento vector que utilizaré a modo de enfoque para pensar cómo la Resurrección ofrece una recuperación del sentido ante el absurdo de la crisis. Con la experiencia del encuentro con el resucitado (con el totalmente otro) los interlocutores pasan (experimentan la pascua) de "no reconocer" a "reconocer" y de "no saber" a empaparse de la presencia siempre nueva del Cristo Pascual.

La presente propuesta se articulará en los siguientes momentos: en primer lugar, la presentación del concepto del imaginario, entendido como la capacidad de ensanchar las fronteras del conocimiento y de la forma en la que interpretamos la realidad y los textos. En segundo lugar, me abocaré a reflexionar las dos metáforas que se proponen, a saber, el "no saber" y su potencial de recuperación de la incertidumbre y, finalmente, el "no reconocer" con la capacidad de transitar pascualmente hacia el recuerdo, la memoria de la voz, de los gestos y del cuerpo.

\section{2.- Aprender a ensanchar las fronteras: el imaginario}

\subsection{El concepto del imaginario}

Dice la narradora y ensayista argentina Graciela Montes: "yo hablo aquí de ensanchar la frontera, de construir imaginarios, de fundar ciudades libres, de hacer cultura, de recuperar el sentido, de no dejarse domesticar, 
de volver a aprender a hacer gestos, a dejar marcas" ${ }^{2}$. Pienso que esta intuición de la ensayista trasandina es aquello que mueve - en parte - el desarrollo que quisiera presentar. El tiempo del estallido social, la época de la pandemia y el futuro tiempo de la post-pandemia, tienen que ver con un centro común: se mueven dentro del imaginario. La experiencia de no saber muy bien hacia dónde nos movemos, la lógica de la incertidumbre, la vivencia de las contrariedades, se podrían entender desde la capacidad que se tiene al momento de ensanchar la frontera. Ensanchar la frontera, para Montes, tiene que ver con la audacia que la palabra poética tiene en medio del imperio de lo calculado, de lo concordante y de lo que aparece como normalizado. Por ello la autora sostiene que la capacidad narrativa, la irrupción de los cuentos, de las fábulas y de los mitos, de lo que ella llama "el territorio del imaginario"3 es, ante todo, una "red de resistencia"4.

A través de la resistencia, propia de la creación de la creación literaria que, tomando prestados elementos de la experiencia cotidiana es capaz de horadar la misma experiencia, es desde donde se propone presentar algunas intuiciones en torno a cómo el acontecimiento de la Resurrección de Jesús ofrece un tipo de imaginario, al que denomino de crisis, el cual puede ayudar a repensar las formas de búsqueda de sentido en un tiempo de profundo quiebre.

Lo interesante del imaginario pasa por la búsqueda de una capacidad altamente creadora de la mente humana, de un cierto tiempo de "despertar", tal y como lo afirma Gastón Bachelard. De esta manera, es que la red de imaginaciones que se pueden proveer al momento de querer comprender la realidad es un elemento del cual se sugiere recuperar su centralidad. Uno de los teóricos que más ha abordado esta cuestión es Gastón Bachelard, hasta el punto de proponer una epistemología de lo imaginario. Para Bachelard la función del imaginario:

"es la facultad de deformar las imágenes suministradas por la percepción y, sobre todo, la facultad de librarnos de las imágenes primeras, de

${ }^{2}$ G. MonTEs, La frontera indómita: en torno a la construcción y defensa del espacio poético, FCE, México $2017^{3}, 59$.

3 G. MONTES, La frontera indómita..., 16.

${ }^{4} \mathrm{G}$. MonTES, La frontera indómita..., 16.

5 Cf. G. BACHELARD, El agua y los sueños: ensayo sobre la imaginación de la materia, FCE, México 2016 ${ }^{6}, 32$. 
cambiar las imágenes. Si no hay cambios de imágenes, unión inesperada de imágenes, no hay imaginación, no hay acción imaginante" .

Desde esta intuición bachelariana, se vuelve a la cuestión central de cómo el imaginario supone esta red de resistencia contra la normalización per se de los elementos que sirven como criterios de reconocimiento e interpretación de la realidad. Al poseer una dinámica altamente provocativa, el imaginario constituye una mirada sub-versiva de un relato fijo. Pero, si se reconocen las funciones propias del psiquismo humano, es posible percibir que lo plástico de la interpretación y de la creación de herramientas y categorías para reconocer aquello que está en la realidad o que la supera en el caso de lo divino, se puede encontrar que el imaginario representa una fuerza de horadación mucho mayor. En palabras de Bachelard: "gracias a lo imaginario, la imaginación es esencialmente abierta, evasiva. Es dentro del psiquismo humano la experiencia misma de la apertura, la experiencia misma de su novedad"7. En otro momento, el filósofo y epistemólogo francés sostiene:

“ante las imágenes que nos proporcionan los poetas, ante esas imágenes que nunca nosotros habríamos podido imaginar por nuestra cuenta, esta inocencia del maravillarse es muy natural. Pero si vivimos con pasividad ese maravillarnos, no participaremos demasiado profundamente en la imaginación creadora. La fenomenología de la imagen nos pide que activemos la participación en la imaginación creadora"8.

Y, más adelante indica: "todos los sentidos se despiertan y armonizan en la ensoñación poética. Y esta polifonía de sentidos es aquello que la ensoñación poética escucha y la conciencia poética debe registrar"9. El imaginario, por tanto, invita a quitar de la mente, del corazón y del espíritu la mirada unívoca de la realidad y de la aproximación interpretativa a ella. Estas imágenes poéticas son aquellas que recrean lúdicamente las categorías y las formas de acceso a los textos, a las preguntas y a sus intentos de respuestas. Por ello el imaginario es fecundo, nunca estático, sino que es extático; está en movimiento, es profundamente dinámico, inventivo y

${ }^{6}$ G. BACHELARD, El aire y los sueños: ensayo sobre la imaginación del movimiento, FCE, México $2017^{11}$, 9.

7 G. BACHELARD, El aire y los sueños..., 9.

${ }^{8}$ G. BACHELARD, La poética de la ensoñación, FCE, México 2014, 14.

${ }^{9} \mathrm{G}$. BACHELARD, La poética de la ensoñación...., 17. 
propositivo. En palabras de Gastón Bachelard:

"un espíritu demasiado geométrico, una visión demasiado analítica, un juicio estético que se obstruye con términos del oficio, son otras tantas razones que detienen la participación de las fuerzas cósmicas elementales. Esa participación es delicada"10.

Con lo anterior, se presenta que la construcción o el establecimiento de imágenes y figuras para comprender la realidad es el centro de la misma propuesta del imaginario. Para la comprensión de dichas perspectivas, uno de los grandes teóricos del uso de los imaginarios es Cornelius Castoriadis $^{11}$. Él considera que el factor clave al momento de comprender el imaginario es el uso del lenguaje. Este filósofo indica que el pensamiento necesita del lenguaje para existir, y que, a su vez, el lenguaje existe dentro de una comunidad humana que lo crea y lo legitima en cuanto expresión de una realidad que busca significar. Esta comunidad tiene el carácter de ser histórica, con lo cual el lenguaje, las metáforas, las figuras y el imaginario nacen de contextos históricos y sociales determinados. Dichos contextos, al estar entramados por una variedad de enunciaciones, experiencias, modos de mirar e interpretar la realidad, hacen que los imaginarios nunca sean unívocos, sino más bien, son equívocos, polisémicos. Estas características son las que, a juicio de César Carbullanca, no posee el texto clásico. Para él:

"el texto clásico tiene un sentido único y esto, paradójicamente en un doble sentido. De un lado se presume que el texto contiene un sentido y es uno solo, de otro lado que el sentido procede unilateralmente del autor y va hacia el lector (...) un texto clásico es una entidad cerrada, clausurada y el sentido radica en la misma materialidad del texto, es decir, es un texto sin cultura, a-histórico" ${ }^{12}$.

Esta distinción entre texto clásico e imaginario resulta clave al momento de comprender el sentido profundo de la segunda experiencia. Se podría expresar incluso una suerte de ampliación del concepto del texto en cuanto a que, con la presencia del imaginario, éste asume el carácter de ser una producción cultural, social e histórica, con incidencia en la comprensión

${ }^{10} \mathrm{G}$. BACHELARD, El derecho de soñar, FCE, México $2017^{4}, 43-44$.

${ }^{11}$ C. CASTORIADIS, "El imaginario social constituyente", http://www.ubiobio. $\mathrm{cl} / \mathrm{miweb} /$ webfile/media/267/Castoriadis\%20Cornelius\%20-\%20El\%20 Imaginario\%20Social\%20Instituyente.pdf, citado, 14 septiembre 2020.

${ }_{12}$ C. Carbullanca, "Exégesis, texto e imaginario", Estudios Teológicos 59/2 (2019), 282-295, 288. 
de una comunidad consigo misma y del proceso de interpretación que dicha comunidad tiene de la realidad que la rodea. En palabras de Armand Puig "el diálogo del texto con el mundo y la historia (...) debe ser siempre contextual, es decir, se debe encarnar y enraizar en la cultura. Si no hay concreción, la hermenéutica del texto queda estéril y sin fuerza” ${ }^{{ }^{13}}$.

Con esto, la interpretación o traducción realizada en el proceso de creación de las imágenes, depende de las motivaciones que están en la base de su creación y de su dimensión comunitaria y social. Este carácter de socialización del imaginario muestra, a entender de Castoriadis, que el ser humano no vive en una suerte de estado puro, sino que siempre está en socialización, y que no existe un pensamiento ingenuo o históricamente neutral. Esto es llamado por Castoriadis como "ensamblado de elementos preexistentes" ${ }^{\prime 4}$. Por este concepto se comprende cómo existe una serie de marcas sociales y conceptuales mayores que nos permiten entendernos en la comunidad de la cual surge el imaginario como espacio de comprensión de lo real. Con ello, la imaginación o el tema del imaginario crean un mundo para la sociedad y van dando lugar a la psique personal y social de los individuos ${ }^{15}$. Son lo imaginarios, por tanto, una representación del mundo.

En relación con esto, y dentro del concepto del imaginario, los autores reclaman la necesidad de pensar un acercamiento antropológico al mismo o de pensar una antropología de lo imaginario. Uno de estos acercamientos es el de Ángel Carretero Pasín. Carretero comienza definiendo al ser humano como un ser "propiamente imaginante"16. La imaginación, como ya se anotó con Castoriadis, pertenece a la psique de cada hombre y mujer, aun cuando el modelo empírico o de la razón instrumental considere que todo lo relativo a la imaginación es solo una ilusión o puede ser considerado como una realidad pre-científica. Esta estructura imaginante del ser humano, como marca constitutiva de la misma existencia humana, manifies-

${ }^{13}$ A. Puig, "Definición y desafíos de una hermenéutica bíblica latinoamericana", Teología y vida 59/4 (2018), 567.

${ }_{14}$ C. CASTORIADIS, "El imaginario social constituyente", en: http://www. ubiobio.cl/miweb/webfile/media/267/Castoriadis\%20Cornelius\%20-\%20El\%20 Imaginario\%20Social\%20Instituyente.pdf, citado 14 septiembre 2020.

${ }_{15}$ Dice Carretero Pasín: "en suma, según Castoriadis, existiría una condición humana sustancialmente imaginante que se expresa por medio de lo simbólico", en: A. CARRETERo PASÍn, "Un acercamiento antropológico a lo imaginario", ÁgoraPapeles de Filosofía 22 (2003), 178.

${ }^{16}$ Cf. A. CARRETERo PASín, "Un acercamiento antropológico...”, 177. 
ta una "antropología de lo profundo que retoma lo arcaico, lo fundante"17 Por ello, el imaginario y al estar fuertemente enraizado en la misma condición humana, se manifiesta a juicio de Carretero como una "estructura de sentido"18. En este mismo sentido Carrera indica que el imaginario se entiende como:

"generatriz en las prácticas cotidianas, sociopolíticas o sacro-sociales, donde lo observable no es el imaginario en sí mismo, sino su incidencia en las representaciones sociales, las construcciones ideológicas, las creencias, la tradición o las acciones sociopolíticas"19.

Por ejemplo, decir "transformación" como concepto, experiencia o imaginario, no significa lo mismo para un grupo o para otro. Es necesario recordar cómo el concepto, cualquiera sea, posee significado, significantes e imágenes acústicas. Por la presencia de estos elementos puede existir diversidad al momento de comprender un determinado concepto. Decir por ejemplo “cuerpo", manifiesta una pluralidad de nociones o interpretaciones que muestran que los imaginarios que surgen de los grupos humanos son variados como variados son los mismos grupos. Desde la lógica de Carrera, expuesta anteriormente, se explicita que un grupo humano no observa el imaginario, sino que interpreta e interioriza las prácticas y creencias que de él surge. Los grupos sociales se mueven gracias al concepto del mismo imaginario. Y algo pasa también con el concepto de Resurrección. Es un concepto amplio, metafórico o polisémico, en cuanto manifiesta distintos significados y posibilidades de construcción teórica y práctica. Es decir, el imaginario permite interpretar la historia y la realidad y, a su vez, genera las pistas para organizar las prácticas que surgen de dicha actividad interpretativa.

El estatuto del imaginario en su relación con la antropología, posee otra arista que es importante recuperar al momento de querer pensar la propuesta de este artículo, a saber, la capacidad de entender el imaginario o las figuras simbólico-metafóricas desde lo estético. Carretero Pasín indica que, en medio de la productividad del mundo moderno, el cual, y a su juicio, genera un vacío de significación en la vida cotidiana, es necesario volver a

${ }^{17}$ A. CARretero Pasín, "Un acercamiento antropológico...”, 179.

${ }^{18}$ A. CARRETERo PASín, "Un acercamiento antropológico...", 181.

19 J. CARRERA, "Entre lo imaginario y lo real. Teorética y reflexividad para una antropología de lo imaginario", Cinta moebio 59 (2017), 144. 
pensar la fantasía, la ensoñación, la imaginación y todos aquellos aspectos que permiten superar el horror al vacío. Carretero Pasín sostiene que "el hombre busca enriquecer su existencia a través de minúsculos sueños, de micromitologías proxémicas, de proyecciones fantasiosas que, así convierten en soportable su vida cotidiana" ${ }^{20}$. Con ello, el imaginario surge incluso como una experiencia de resistencia ante las faltas antropológicas que genera el excesivo racionalismo, la urgente impronta empírica o la razón instrumental, o como intuye Juan Carrera en cuanto el imaginario invita al "cuestionamiento del orden establecido" 21.

Ante estas situaciones, Carretero comenta la función del imaginario en los siguientes términos: "ante la imposibilidad real de canalizar y materializar su imaginación en el orden tecno-productivo cotidiano, el ser humano alza un clandestino mundo imaginario que colma una compensadora ficción a su vida y estetiza su existencia" ${ }^{22}$.

Estetizar la existencia significa aprehenderla en su realidad más profunda y en su necesaria multidimensionalidad, en ese exceso de sentido que poseen todas las imágenes, metáforas y símbolos. De alguna manera ese carácter de resistencia que poseen la poesía, las propuestas filosóficas, teológicas, los sueños, las esperanzas, el anhelo del proyecto, tienen que ver con lo estético del imaginario y con la capacidad de mirar estéticamente la realidad, de ser capaces de comprenderla en su dimensión más profunda.

Esta dimensión estética es de tal importancia al momento de pensar el imaginario que autoras como Patricia María Calvo piensan el concepto de "imaginario estético como locus epistemológico" ${ }^{23}$, el cual surge cuando la imagen trasciende a sí misma en su apertura y va descubriendo una verdad oculta de la realidad. Las cualificaciones del origen, de la convivencia, de las relaciones interpersonales y con la naturaleza, las formas de morir y de entender la muerte y las experiencias de salvación están contenidas en esta estatización de la vida cotidiana propia del imaginario. Juan Carrera, a propósito de esto, indica: "el concepto imaginario reviste un orden polisémico por excelencia, es la incertidumbre cognoscitiva de comprender un

${ }^{20}$ A. Carretero Pasín, "Un acercamiento antropológico...”, 183.

${ }^{21}$ J. CARRERA, "Entre lo imaginario y lo real...", 148.

${ }^{22}$ A. CARRETERo PASín, "Un acercamiento antropológico...", 183.

${ }^{23}$ P. M. Calvo, "El imaginario estético como locus antropológico. Hacia una antropología del imaginario", Teoliterária 3/5 (2013), 132. 
componente esencial de la cultura; la memoria, las creencias o las tradiciones de los grupos en relación con un contexto determinado, vale decir, las formas de ser y hacer de los individuos"24. Las formas del imaginario permiten que la realidad se simbolice y, desde ahí, poder proyectar nuevas formas de comprensión de la realidad misma y de sus acontecimientos más fundamentales, de aquellas experiencias que han trocado, por ejemplo, la vida de una comunidad.

\subsection{La Resurrección: apertura desde el imaginario y la metáfora a la experiencia de la Vida}

Es más, el caso mismo de la comprensión de la Resurrección surge a partir de una mirada metafórica y más cercana al imaginario. Hans Kessler, en su obra sobre La Resurrección en su aspecto bíblico, teológico y sistemático, indica que el concepto mismo de la Resurrección se expone desde un profundo sentido metafórico, el cual es llamado por el autor como "lenguaje encubridor" ${ }^{25}$ en cuanto oculta un profundo misterio que es necesario ir descubriendo en un proceso de traducción novedosa.

Kessler sostiene que el sentido metafórico de la Resurrección manifiesta que "la estructura metafórica del lenguaje encierra la posibilidad de la innovación y del alcance hacia lo inexplorado" ${ }^{26}$. La metáfora trabaja con lo extraño, con la intriga y lo no absolutamente entendido, con lo no habitual, con lo fuera de lo común. La imagen metafórica, la figura estética, el imaginario lingüístico como mediación del conocimiento aplicado, en este caso, a la teología, aparece como una actividad por la cual se desestructura el horizonte, de decir que lo empírico no es sólo lo real, sino que los conceptos mismos expresan una realidad certera. En palabras del mismo Kessler: "y expresa con ellos, gracias al empleo metafóricos en el horizonte del mundo algo que rebasa el horizonte" 27.

Asumimos, por tanto, la urgencia epistémica de estetizar la realidad, es decir, de buscar los significados más profundos de lo humano y comprender cómo el Misterio de la Resurrección de Jesús impacta significati-

${ }^{24}$ J. CARRERA, "Entre lo imaginario y lo real...”, 145.

${ }^{25}$ H. KESSLER, La resurrección de Jesús: aspecto bíblico, teológico y sistemático, Sígueme, Salamanca 1989, 228.

${ }^{26}$ H. KESSLER, La Resurrección... 228.

${ }^{27}$ H. KESSLER, La Resurrección.... 229. 
vamente en la práctica cotidiana y en la formulación de la ciencia teológica, de la espiritualidad y de los modos que tenemos de afrontar las crisis que surgen en nuestro tiempo. De esta manera, las metáforas, los imaginarios, las figuras, son formas en las que el discurso habla como una narrativa no clausurada sino abierta y siempre en camino. Son "saltos imaginativos" 28 con apariencia lúdica y sentido profundamente desestabilizador. Es un modo por el cual el ser humano "se atreva a pensar de modo diferente" 29. Ante ello, autores como Adolphe Gesché, insisten en que el concepto, así como otras palabras relativas muestran que "estamos mucho más allá de una realidad que sería perceptible con una lectura demasiado rápida y exclusivamente material" ${ }^{30}$.

\subsection{El método propuesto para este artículo}

El modo de acercarme al tema que quisiera presentar será movido por una lectura espiritual de la realidad, recuperando metáforas e imaginarios, y tratando de pensar la dimensión salvífica de la vulnerabilidad presente en el no saber y el no reconocer en cuanto imaginarios presentes en la Resurrección de Jesús. Quisiera pensar en lo lúdico de la lectura imaginaria de los textos, no entendiendo por "imaginaria" la no realidad de estos. Eso, pienso, es lo que hace del imaginario tal cosa, a saber, la capacidad de proponer un lenguaje de lo distinto en cuanto las experiencias, cualquiera sea, nos llegan por caminos de profunda distinción, crisis y sorpresa. En palabras de Graciela Montes:

"por esa manera de horadar que tiene la ficción. De levantar cosas tapadas. Mirar al otro lado. Fisurar lo que parece liso. Ofrecer grietas por donde colarse. Abonar las desmesuras. Explorar los territorios de frontera, entrar en los caracoles que esconden las personas, los vínculos, las ideas" ${ }^{31}$.

El imaginario de la crisis, expresado y representado por medio de las imágenes, vínculos, ideas, fronteras, grietas referidas al tema que queremos abordar, lo buscaré entender desde dos expresiones metafóricas des-

${ }^{28}$ S. McFague, Modelos de Dios: teología para una era ecológica y nuclear, Sal Terrae, Santander 1994, 73 .

${ }^{29}$ S. McFague, Modelos de Dios..., 75.

${ }^{30}$ A. Gesché, Dios para pensar: Jesucristo, Sígueme, Salamanca 2013, 149.

${ }^{31} \mathrm{G}$. MONTES, La frontera indómita..., 28. 
prendidas de los relatos evangélicos relativos a la Resurrección. Ellas son el "no saber", presente en el relato de los discípulos de Emaús y, en segundo lugar, el "no reconocer" presente en los textos del Evangelio de Juan referidos al encuentro de Magdalena con el Resucitado y de éste con los discípulos en el Lago de Galilea. Pienso que, en ambos casos, el centro metafórico involucra la falta de puntos de referencia o de sentido por medio de los cuales podemos entender (entender-nos) la realidad y a nosotros en ella. Eso, quizás, ha provocado la época presente en cuanto puesta en suspenso, intriga o incertidumbre de las cuestiones normales y cotidianas. Y es justamente en medio de esas situaciones en donde el Resucitado irrumpe para resucitar nuestros elementos de sentido y a nosotros en ellos.

En medio de nuestra época de pandemia, de falta de puntos de anclaje, de presencia de modelos de deshumanización, de nuestras crisis eclesiales, pienso que el recurso teológico a los imaginarios nos puede aportar una visión más amplia y más sugerente al momento de leer, pensar, vivir y celebrar los acontecimientos fundamentales de la fe que son testimoniados por los textos de la Biblia. Volver a imaginar, a proponer nuevas lecturas de los relatos, ejercitar los sueños en vistas a lo estético y al sentido de los textos, supone un acercamiento sugestivo a los textos. No es en ningún momento una lectura antojadiza de los relatos, en nuestro caso evangélicos. Es, más bien, un ejercicio de lectura antropológica de los testimonios sobre la Resurrección de Jesús en vistas a pensar qué nos dice hoy a nosotros este acontecimiento fundamental para la vida cristiana.

\section{3.- "No saber": la recuperación de la incertidumbre como ele- mento constitutivo de la vida humana}

La primera metáfora, el "no saber", está puesta por Lucas en boca de Jesús Resucitado no reconocido por los discípulos. Dice el relato: "uno de ellos, llamado Cleofás, le respondió: ¿eres tú el único residente en Jerusalén que no sabe (egnos) las cosas que han pasado allí estos días?” (Luc 24,18). Generalmente, la lectura del texto coloca su primera atención en el no reconocer de los ojos de los discípulos en el versículo 16. Quisiera recuperar el no saber de Jesús como espacio pedagógico de recuperación de y en la incertidumbre, en cuanto elemento constitutivo de la vida humana. Luego de la intervención de los discípulos, Jesús irrumpe con una pregunta: “¿qué cosas” (Lc 24,19), la cual se entiende desde la primera pregunta 
aparecida en el relato: “¿de qué discuten por el camino?” (Lc 24,17). El no saber y su vínculo con las preguntas, permiten que el diálogo comience a desarrollarse en la lógica del camino.

Nuestra época nos ha acostumbrado a vivir la lógica del gnos, del conocer, y conocer todo, de tener respuestas certeras en todos los ámbitos posibles. Con Emaús, con la pandemia, con la irrupción de los conflictos, aparece, en cambio, la idea del egnos (agnos) del no saber, del reconocer que las respuestas que poseíamos no eran suficientes para poder dar resolución a las cuestiones más acuciantes en las que nos movíamos. Al decir de Rebeca Yanke, "lo único cierto es lo incierto"32. Ella indica:

"una cultura como la nuestra vive la incertidumbre como algo negativo porque tendemos a querer dominar la realidad, pero hay un aspecto necesario para la evolución del ser humano: desarraiga de la tendencia a encerrarnos en hábitos mentales, estructurar espacios y tiempos como en un cuartel, y reducir nuestra vida a lo que podemos comprender. La incertidumbre puede ayudarnos a controlar el ego hipertrófico que nos empuja a acumular conocimiento utilizando siempre el mismo lenguaje, es una oportunidad para descubrir lenguajes nuevos dentro de nosotros" 33 .

La incertidumbre tiene una profunda función pedagógica. Con el "no saber" nos adentramos en el nuevo conocimiento de las cosas. Al comienzo fue el "no saber" que permitió el surgimiento del gnos. En el acontecimiento de la Resurrección entramos en la lógica de la intriga, tal y como han expuesto autores como Adolphe Gesché. El centro del relato en el cual incide el imaginario es Jesús mismo. Por eso Gesché indica: se diría que Jesús pide que le cuenten, y que le cuenten a él mismo" 34 . Por medio de la intriga evangélica, indica Gesché, se anima al lector a participar del proceso de "adivinar que Jesús es el Cristo ${ }^{35}$.

Con la intriga, como principio narrativo de la incertidumbre, en cuanto que las experiencias del no saber son básicamente narradas, es necesario

32 R. YANKe, "Lo único cierto es lo incierto", en https://lab.elmundo.es/ coronavirus/incertidumbre.html, citado 2 octubre 2020.

33 R. YANKE, "Lo único cierto es lo incierto", en https://lab.elmundo.es/ coronavirus/incertidumbre.html, citado 2 octubre 2020.

${ }^{34}$ A. Gesché, Dios para pensar: Jesucristo..., 94-95.

${ }^{35}$ Cf. A. Gesché, Dios para pensar: Jesucristo..., 99. 
recuperar lo que el mismo Gesché articula bajo la categoría de una "epistemología del silencio" ${ }^{36}$, la cual en sí misma, es pedagógica en cuanto permite la abertura a un conocimiento transformador que es iniciado por el mismo Jesús.

En el caso de Emaús, el comienzo está enmarcado en la pregunta. Por ello insiste Gesché: “el silencio (de Jesús) debe preceder a la palabra (del apóstol) para que ésta quede liberada" ${ }^{37}$. En el tiempo de la incertidumbre los silencios tienen más valor que la palabra. Eso es algo profundamente paradójico, en cuanto no hemos sido capaces de comprender, interiorizar o ser educados en que la incertidumbre, el no saber (puesto en los labios mismos de Jesús) son elementos positivos, inaugurales, descoincidentes. Por ello es que comprendemos las grietas y las fisuras de las que hablaba Graciela Montes. El silencio, la intriga y lo incierto son los elementos que agujerean la supuesta supremacía del saber.

En la lógica de la Resurrección de Jesús, la vida nueva del que es la Palabra es antecedida por el Silencio. En Cristo Resucitado aparece una vinculación dialéctica entre Silencio-Palabra, entre "no saber"- "saber”. Quizás el "no saber" del Cristo de Emaús es más que un artificio literario del tercer Evangelio, y tiene que ver con una realidad que, en el mismo Jesús, se nos comunica como lugar salvador. Quizás en ese no saber es donde encontramos la dimensión salvífica de la Resurrección vivida en la más profunda vulnerabilidad de la muerte y del no saber. Lo que aconteció en la Resurrección nadie lo supo. Vieron el sepulcro vacío, escucharon a las mujeres contar (nuevamente el terreno de la narrativa y del imaginario) que habían visto unos ángeles que les habían dicho algunas cosas. Ese es el misterio del no saber que, quizás, en nuestra época de pandemia se ha instalado como una prolongación del mismo Evangelio y del mismo Dios. La crisis de la Resurrección se articula, por tanto, en ese espacio de silencio que no debe ser llenado apresuradamente, sino que debemos permitir que se nos revele incluso en su incómodo no saber.

${ }^{36}$ A. GESCHÉ, Dios para pensar: Jesucristo..., 109.

${ }^{37}$ A. GESCHÉ, Dios para pensar: Jesucristo..., 109. 


\section{4.- "No reconocer": camino hacia el recordar}

El Evangelio de Juan y sus relatos de la Resurrección, quisiera entenderlos a partir de la metáfora o del imaginario del "no reconocer". En el caso de Magdalena y su confusión que hace que no reconozca a Jesús haciéndolo pasar por jardinero (Cf. Jn 20,14) y la situación de los discípulos pescando en el lago que no reconocen a Jesús en la orilla (Cf. Jn 21,4), son narraciones que se enmarcan dentro de este imaginario de la crisis que queremos proponer.

Lo interesante será entender cómo desde el "no reconocer" - y con la Resurrección - acontece una pascua hacia el recordar gracias a los gestos, signos, voz y la presencia de Jesús. Pienso que lo que resulta más sanador en medio de nuestra época de pandemia es abrirnos a la posibilidad de recordar (re cordis, volver a pasar por el corazón, hacer memoria, mantener vivos los recuerdos, los rostros, el eros, las vinculaciones, los sentidos y sentimientos) que Aquél que estuvo con los discípulos en su ministerio público es el mismo que le sale al encuentro resucitado. La Resurrección, con ello, es un trabajo que el Señor realiza sobre nuestras vulnerabilidades, fragilidades, incertidumbres. Por lo tanto, el imaginario de la crisis no es una im-posibilidad, sino una posibilidad de reconstituirnos como sujetos.

¿Qué elementos son los que, desde Jesús, permiten el paso, la pascua o la conversión entre el no reconocer y el recordar? A continuación, se propondrán tres elementos que se desprenden del encuentro con Jesús en ambos relatos joánicos y que se pensarán como espacios de recuperación de nuestro sentido.

\section{a) El cuerpo ausente}

Autores como Jean-Daniel Causse reconocen que la mejor forma de comprender la resurrección de Jesús es a partir de una "radical discontinuidad" ${ }^{38}$, de una experiencia que en sí misma es crítica y, por tanto, no es fácilmente legible o entendible. Al tratar con un acontecimiento que supera la lógica histórica, el modo de acercarse a ella es a partir de la

${ }^{8}$ J-D CAusse, El don del agapé: constitución del sujeto ético, Sal Terrae, Santander 2006, 113. 
paradoja, de la ausencia o la falta. Causse, a propósito de los relatos en torno al acontecimiento, indica que "éstos tienen la función de circunscribir un espacio vacío o delimitar un lugar con el que choca siempre el lenguaje" 39 . Se accede desde la im-posibilidad del decir hacia la posibilidad del encuentro. Pienso incluso que ese tránsito puede constituir un espacio donde se recupere la misma i-lógica de una pandemia, de la ausencia, de la enfermedad, del fracaso y de la muerte. Y digo i-lógica en cuanto estas situaciones suponen el quiebre de un sentido común y normal (o en apariencia normal, o al que nos acostumbraron a llamar normal). Pero, resulta clave entender que son i-lógicas en su propia y natural lógica. Olvidar que la ausencia, el dolor, la enfermedad, la muerte o el quiebre son elementos propios de la vida humana nos termina deshumanizando.

Michel de Certeau aporta elementos similares a los de Causse. De Certeau, y en el caso específico del morir, el autor indica que la muerte tiene que ver con algo deseado que es imposible poseerlo ${ }^{40}$. Aquí aparece nuevamente la ausencia. Incluso, autores como Olivier Clement, desde la tradición ortodoxa, ven en Getsemaní un preludio de la ausencia del cuerpo ausente. Dice Clement: "en el Gólgota, al igual que en Getsemaní, Dios experimenta humanamente la ausencia de Dios, el silencio de Dios, así como esta sed febril en el vacío donde hoy nos hallamos todos" ${ }^{41}$.

El vacío del que habla Clement, el deseo no satisfecho de De Certeau o la radical discontinuidad en la experiencia de la ausencia de Causse, van confluyendo para poder entender el cómo de la Resurrección en cuanto experiencia de vivir el cuerpo ausente. Desde aquí, y en sintonía con el tiempo presente, sería imposible reducir el cuerpo ausente del CrucificadoResucitado a una fría teoría. Todos en este año hemos vivido la ausencia del cuerpo del otro: nuestras familias, nuestros estudiantes, los compañeros de trabajo o los amigos. Y, también, hemos experimentado la im-posibilidad de acercarnos a acompañar a nuestros muertos y a nuestros deudos. $\mathrm{O}$, también, algunos han experimentado la ausencia del trabajo y del sueldo. Todas estas ausencias, quisiera ver, toman sentido o posibilidad en la im-

39 J-D Causse, El don del agapé..., 113.

${ }^{40} \mathrm{Cf}$. M. De CCerteau, La invención de lo cotidiano: artes de hacer, Tomo I, Universidad Iberoamericana, México 2007, 210.

${ }^{41}$ O. Clement, La alegría de la resurrección: variaciones sobre la Pascua, Sígueme, Salamanca 2016, 65. 
posibilidad del cuerpo torturado y maltratado que ya no puede ser encontrando en la tumba.

\section{b) La voz}

Y, aunque Él no puede ser encontrado en la tumba, sí podemos escuchar su voz y, escuchándola terminamos recordándola. ¿Por qué, a pesar de la distancia y de la ausencia, el otro continúa siendo significativo? En uno de los momentos críticos de la pandemia el autor de este texto propuso una columna titulada "La memoria del eros"42 en la cual se intentó dar una respuesta a esta pregunta.

El cuerpo y el entender que el ser humano es esencialmente cuerpo, como dice Bernard Sesboüé43, ayuda a interiorizar que la voz, como espacio comunicativo, interpersonal, constructor - y destructor - provocativo o evocativo, es una forma utilizada por el Resucitado para tornarse experienciable ante los discípulos. En ambos casos, Magdalena y los discípulos, el encuentro está inaugurado por la voz que pregunta por el llanto o por el pescado respectivamente (Cf. Jn 20,15; Jn 21,5). Emaús también posee la voz de Jesús que aparece entre las preguntas.

$\mathrm{Y}$, de un modo particular, la voz familiar de Jesús resucitado es lo que permite que Magdalena y los discípulos reconozcan (vuelvan a entrar en intimidad, desde el conocer hebreo) y recuerden que el que pronuncia palabras al comienzo del día sea Jesús. En el relato de Magdalena, es Jesús quien se dirige e interpela a la mujer. Dicha interpelación se torna en llamada por el nombre: María (Jn 20,16). A los discípulos en el lago de Galilea (Juan 21), Jesús les indica que echen la red hacia la derecha de la barca porque ahí es donde encontrarían el fruto del esfuerzo (Cf. Jn 21,6). Y fue gracias a esta práctica conocida, que el discípulo amado (el que tiene intimidad con Jesús) lo recuerda y le reconoce diciendo: "es el Señor” (Jn 21,7).

Una de las cosas que personalmente más me impactan de los relatos de Resurrección es que en ellos percibimos cómo ella nos acontece en cuanto

42 J. P. EsPinOSA, "La memoria del eros" http://www.reflexionyliberacion.cl/ ryl/2020/08/04/la-memoria-del-eros/, citado 4 agosto 2020.

${ }^{43} \mathrm{Cf}$. B. SEsBoüÉ, Creer. Invitación a la fe católica para las mujeres y los hombres del siglo XXI, San Pablo, España 2000, 357. 
somos interpelados, en cuanto se nos dirige una palabra, en el momento en que la voz resuena. Esto lo presenta Causse en las siguientes palabras: "el acontecimiento "resurrección" no tiene lugar más que en el momento en que María oye cómo alguien se dirige a ella por su nombre y, efectuando el gesto simbólico de darse vuelta, reconoce a ese alguien. El significante "resurrección", en cuanto que designa a Cristo (yo soy la Resurrección), no tiene efectividad más que en el instante en que María adviene como sujeto nuevo"44.

La creación de una nueva forma de ser, de una verdadera pascua antropológica y cósmica, integrada, integral, respetuosa, cordial, con recuerdos, sensaciones, eros, agapé, comunidad, política, ecología, etc. es lo que estamos contemplando en los relatos de la resurrección que, enmarcándose en un imaginario crítico - iporque la Resurrección, crítica del viejo modelo, aconteció en medio de la crisis de la comunidad! - nos movilizan a salir del espacio reductivo del pequeño yo de manera de dejarse modelar por aquella voz que, siendo familiar, es siempre nueva. La voz del cuerpo ausente, cualquiera sea, aún resuena en nosotros - porque podemos recordarla - y nos recuerda que todavía queda un sentido: el amor, el vínculo, el encuentro, la Pascua.

\section{c) El gesto}

Del cuerpo ausente a la voz; y de la voz al Resucitado que gesticula con Magdalena y los discípulos. La resurrección está preñada de gestos, de movimientos, de idas y retornos. Por ello la vida es pascual. En los relatos que se han propuesto revisar, se observa cómo Jesús realiza gestos muy concretos. En Magdalena, Jesús se acerca y dialoga con la mujer que llora (Cf. Jn 20,16-17) y, dialogando, la envía a anunciar a la comunidad de discípulos que Él ha resucitado (Cf. Jn 20,17-18). En el Lago de Galilea - así como en Emaús - Jesús se sienta a la mesa, prepara comida y bendice los alimentos (Cf. Jn 20,9-14). Dos gestos que marcan la misma lógica: el paso de la carencia a la abundancia, del tránsito pascual de la ausencia a la presencia.

El gesto supone un cuerpo que lo enuncia y lo concretiza. El ser humano es cuerpo de gestos y, con el cuerpo se va gesticulando. Con el cuerpo,

${ }^{44}$ J-D. CAusse, El don del agapé... 115. 
hombres y mujeres se vinculan entre sí, se vinculan con el mundo, con ellos mismos y también con Dios. El Resucitado, que posee un cuerpo transformado, transforma la realidad presente en cuanto anticipación de la zoé en la biós. Desde la sabiduría oriental ortodoxa, Clement inquiere: "en el Adán definitivo la carne precaria, sometida a la finitud y a la muerte, se vuelve carne de resurrección, cuerpo de gloria"45. La transformación, deificación, también llamada humanización, surge desde un gesto que viene a posicionarse en medio de lo cotidiano haciendo de esta experiencia algo sagrado. Por ello, autores como Fabrice Hadjad indica que "las apariciones del Resucitado tienen un carácter eminentemente práctico" 46 , tan práctico como ser llamados por el nombre, tan práctico como preparar desayuno, dar comida, celebrar juntos la no-muerte. Por ello la Resurrección de Jesús y su vivencia cotidiana asumen elementos profundamente sapienciales, es decir, abren la capacidad de mirar teológicamente los hechos humanos en su sagrada profundidad.

Finalmente, quisiera pensar los gestos humanizadores como espacios donde podríamos saber descubrir cada día los signos de la resurrección que hay a nuestro alrededor. En nuestro tiempo de pandemia pienso que hay una importancia en la recuperación del valor pascual del gesto, de sus emociones, de los sentidos, del cuerpo y de las formas que nos definen como seres amorosos. El cuidado, la ética de la responsabilidad, las formas de lo cordial, sobre todo en nuestro tiempo, pienso, pueden representar espacios iluminados por la resurrección que se anticipa en la historia. Magdalena y los discípulos son testigos de dicho valor, y por ello sus relatos y experiencias son paradigmáticas, en cuanto ellas dan sentido a nuestras propias experiencias gestuales.

\section{Conclusión}

Al finalizar este trabajo que buscó proponer una lectura espiritual y antropológica a la experiencia de la Resurrección en profunda sintonía con la realidad de nuestro tiempo pandémico, lectura realizada desde el foco del

45 O. Clement, Teopoética del cuerpo, carne mortal destinada a la gloria, Sígueme, Salamanca 2017, 24.

${ }^{6}$ F. HADJAD, Resurrección: experiencia de vida en Cristo resucitado, BAC, Madrid 2019, 11. 
imaginario, quisiera consignar algunas breves ideas a modo de recapitulación de lo ofrecido en este artículo.

En primer lugar, la importancia de continuar ampliando nuestros acercamientos al mundo de los relatos bíblicos. En la Palabra encontramos un importante lugar desde el cual podemos hacer experiencia de Dios. La comunidad que lee los textos bíblicos, que se deja interpelar por la Pascua de Jesús y que busca pensar cómo dicho acontecimiento transformador tiene que ver con sus historias particulares, podría encontrar en el imaginario, como pista de lectura bíblica, una sugerente forma de comprender cómo el Resucitado tiene que ver con nuestra vida cotidiana y cómo nuestra vida cotidiana es un espacio de reconocimiento de su presencia amorosa y transformadora.

En segundo lugar, el reconocimiento de nuestro tiempo. Hemos de convertirnos en buenos lectores de nuestros contextos, por ejemplo, el tiempo de la pandemia. Este momento histórico es desafiante y nos invita a mirar la crisis, la incertidumbre y el dolor desde una perspectiva nueva, más cercana y con incidencia en nuestro vivir cotidiano. La crisis, manifestada en el no saber y en el no reconocer, como figuras temporales, humanas y bíblicas, nos puede enseñar a vivenciar de manera más amplia y profunda lo que cada uno de nosotros es.

En tercer lugar, la siempre importante consideración del trabajo interdisciplinario en nuestra formación, investigación, docencia y divulgación teológica. En este artículo hemos leído lo referente a la Resurrección a partir del imaginario, de la antropología, desde lo estético y desde la pandemia y su crisis. El desafío de construir una teología sincrónica con el tiempo y sus demandas, con sus aportes hermenéuticos y científicos, con sus formas de ser, es una cuestión que, pienso, enriquece mucho nuestra labor teológica y le regala un cariz distinto, un sentido atento al tiempo y un sentido de abrazar las experiencias cotidianas de cada uno de nosotros. 


\section{Bibliografía}

BACHELARD B., El derecho de soñar, FCE, México $2017^{4}$.

, El aire y los sueños: ensayo sobre la imaginación del movimiento, FCE, México $2017^{11}$

, El agua y los sueños: ensayo sobre la imaginación de la materia, FCE, México 2016 6 .

, La poética de la ensoñación, FCE, México 2014.

Calvo P. M., "El imaginario estético como locus antropológico. Hacia una antropología del imaginario”, Teoliterária V.3-N.5 (2013), 128-136.

Carbullanca C., "Exégesis, texto e imaginario", Estudos Teológicos v.59 n.2 (2019), 282-295.

CARrera J., "Entre lo imaginario y lo real. Teorética y reflexividad para una antropología de lo imaginario", Cinta moebio 59 (2017), 143-156.

CArretero Pasín A., "Un acercamiento antropológico a lo imaginario”, ÁgoraPapeles de Filosofía 22 (2003), 177-187.

CAstoriadis C., "El imaginario social constituyente", http://www.ubiobio. $\mathrm{cl} / \mathrm{miweb} /$ webfile/media/267/Castoriadis\%20Cornelius\%20-\%20El\%20 Imaginario\%20Social\%2oInstituyente.pdf, citado 14 septiembre 2020.

CAUSSE J., El don del agapé: constitución del sujeto ético, Sal Terrae, Santander 2006.

CERTEAu M., La invención de lo cotidiano: artes de hacer, Tomo I, Universidad Iberoamericana, México 2007.

Clement O., La alegría de la resurrección: variaciones sobre la Pascua, Sígueme, Salamanca 2016.

CLEMENT O., Teopoética del cuerpo, carne mortal destinada a la gloria, Sígueme, Salamanca 2017.

EsPinosA J. P., "La memoria del eros" http://www.reflexionyliberacion.cl/ ryl/2020/o8/04/la-memoria-del-eros/, citado 4 agosto 2020.

Gesché A., Dios para pensar: Jesucristo, Sígueme, Salamanca 2013.

HADJAD F., Resurrección: experiencia de vida en Cristo resucitado, BAC, Madrid 2019.

KeSSLER H., La resurrección de Jesús: aspecto bíblico, teológico y sistemático, Sígueme, Salamanca 1989.

Mcfague S., Modelos de Dios: teología para una era ecológica y nuclear, Sal Terrae, Santander 1994 
Montes G., La frontera indómita: en torno a la construcción y defensa del espacio poético, FCE, México $2017^{3}$.

Puig A. "Definición y desafíos de una hermenéutica bíblica latinoamericana", Teología y vida 59/4 (2018), 563-572.

SESBoüÉ B., Creer. Invitación a la fe católica para las mujeres y los hombres del siglo XXI, San Pablo, España 2000.

YANKE R., "Lo único cierto es lo incierto", en https://lab.elmundo.es/ coronavirus/incertidumbre.html, citado 2 octubre 2020. 